\title{
Uma leitura dos espaços urbanos amazônicos a partir dos referenciais da geografia Miltoniana
}

\section{A reading of the Amazonian urban spaces from the references of the Miltonian geography}

Cláudia Pinheiro Nascimento ${ }^{1}$

\section{RESUMO}

A complexidade do processo de urbanização da Amazônia tem levado a estudos que pouco conseguem compreender o fenômeno na sua totalidade, por utilizar conceitos geográficos que não conseguem abranger todo o universo de pesquisa. Milton Santos, a partir do desenvolvimento de uma teoria para a geografia, construiu uma base de teorização embasada na produção do espaço, a partir da identificação de categorias analíticas que reproduzem, no âmbito das ideias, a totalidade dos processos tal como se reproduzem na realidade. Sendo assim, este artigo busca demonstrar como se deu a evolução da geografia enquanto ciência e as contribuições da teoria miltoniana para a compreensão da leitura acerca da construção dos espaços urbanos amazônicos.

Palavras-Chave: Urbanização, Amazônia, Geografia, Milton Santos

\section{RESUMEN}

La complejidad del proceso de urbanización de la Amazonia ha llevado a estudios que poco han conseguido comprender su totalidad, por utilizar conceptos geográficos que no consiguen abarcar todo el universo de la investigación. Milton Santos a partir del desarrollo de una teoría para la geografía, construyó una base de teorización embasada en la producción del espacio, a partir de la identificación de categorías analíticas que reproducen no alcance de las ideas, la totalidad de los procesos tal como se reproducen en la realidad. Siendo así, este artículo busca demostrar cómo se dá la evolución de la geografía como ciencia y las contribuciones de la teoría miltoniana para una comprensión de la lectura sobre la construcción de los espacios urbanos amazónicos.

Palabras-Clave: Urbanización, Amazonia, Geografía, Milton Santos.

\footnotetext{
ABSTRACT

${ }^{1}$ Formada em Geografia pela Universidade Estadual de Santa Catarina, mestre em Geografia pela Universidade Federal de Rondônia (UNIR), Doutora em Ciências pela Universidade Do Estado do Pará - Núcleo de Altos Estudos Amazônicos (NAEA). Atualmente é professora dos cursos de Geografia e Pedagogia do Centro Universitário UniProjeção.
} 
A complexity of urbanization on the Amazon has led to a study that obtained a small amount of phenomena in its totality, to use geographical concepts that did not reach to cover the whole universe of the research. Milton Santos built a statement of theorization based on the spatial production as a theory for a geography, from the identification of analytical categories that reproduce in the scope of ideas, a totality of the processes as they propagate. Thus, this article tries to demonstrate how an evolution of the geographic science and of contributions of the Milton's theory to understand of the reading on the construction of the Amazonian urban spatial took place.

Keywords: Urbanization, Amazônia, Geography, Amazônia.

\section{Introdução}

Este artigo tem como finalidade principal responder como a teoria de Milton Santos, do espaço como instância social e seus conceitos, pode responder sobre a diversidade do urbano na Amazônia, a partir de uma reconstrução metodológica dos seus aspectos lógicos, epistemológicos e ontológicos. Visando alcançar tal objetivo, baseou-se a busca da resposta em duas leituras epistemológicas da interação do sujeito e do objeto, propostas por Oliveira Filho (1976, p. 265).

A primeira leitura epistemológica denominada genética ou diacrônica permite apresentar a estrutura do conhecimento científico, através da gênese histórica dos conceitos, teorias, explicações e técnicas científicas da ciência geográfica, que redundará numa história da ciência geográfica que não estará necessariamente, voltada a uma concepção linear. Neste primeiro momento é possível observar como as transformações referentes as questões sociais influenciaram na mudança da estrutura, nos paradigmas e conceitos da geografia, além da sua contribuição para a construção do seu objeto atual.

O segundo momento privilegia a condição atual da ciência geográfica, iniciada a partir da década de 1970, com foco no objeto atual da geografia, o espaço social, no qual é possível encontrar a razão da atividade científica da geografia, numa interação entre níveis de conhecimento científico: universo de pesquisa, sistema tecnológico (métodos e técnicas de pesquisa), sistema teórico (hipóteses, conceitos, esquemas conceituais e teorias) e metateórico (fundamentos lógicos, epistemológicos e ontológicos) Oliveira Filho (1976, p. 268).

Cabe ainda uma discussão sobre os aspectos interdisciplinares e multidisciplinares dentro da ciência geográfica e nos aspectos de sua evolução científica. Por fim, a reconstrução metodológica da geografia atual a partir de seus pressupostos epistemológicos, lógicos e ontológicos no intuito de identificar os conceitos e teorias geográficas que permitem compreender a diversidade do urbano na Amazônia.

\section{Evolução da Geografia e de seus conceitos}

A geografia ao longo da sua construção histórica como ciência, já apresentou diversos objetos de estudo e segundo Dresch (1948, p. 88 apud Santos, 2004, p.29) foi desde o seu início uma ideologia, e não uma filosofia, não somente na Alemanha, onde nasceu, mas no mundo inteiro.

Revista de Estudos Sociais | Ano 2017, N. 39, V. 20, Pag. 54 
A ideologia engendrada pelo capitalismo no momento de sua implantação que tinha como foco a sua expansão nos países centrais e na periferia, acabou por influenciar uma gama de geógrafos que utilizaram a geografia como instrumento de conquista colonial. É desse periodo as noções de determinismo geográfico, quando a geografia apresentava-se como intérprete das condições naturais, sendo este o fator responsável pelas relações entre os países desenvolvidos e subdesenvolvidos. Entre os geógrafos coloniais podemos citar A. Himley, Paul Vidal De La Blache, M. Dubois, Charles Robiquain, da escola francesa, e Mackinder, da escola inglesa.

O conceito de espaço utilizado até esse periodo foi o conceito de espaço absoluto, o espaço independente, existindo por si mesmo, separadamente da matéria e possível de se definir por meio de um sistema de coordenadas cartesianas, como latitude e longitude (Machado, 1997).

A ciência geográfica se institucionalizou como disciplina nas universidades europeias entre os períodos de 1870 a 1950, tendo como característica o cunho informativo, período que se inicia uma incipiente reflexão teórica. Essa reflexão estava ligada ao fato da geografia focar seus estudos na sociedade, privilegiando conceitos ligados à ação humana de modelagem da superfície da terra e que apresentam uma forte ligação, surgindo conceitos como: paisagem, região, espaço, lugar e território. Foi a concepção de espaço relativo que dominou os estudos geográficos até aproximadamente a década de 50 , subsidiando uma investigação que priorizava a observação e descrição de fenômenos variados presentes na superfície terrestre (Machado, 1997).

A ciência geográfica percorreu um longo caminho que permitiu um aprimoramento dos seus conceitos, após a sua institucionalização como disciplina nas universidades europeias, entre os anos de 1870 e 1950, temos a chamada revolução teorético-quantitativa ou geografia tradicional. A geografia tradicional privilegiou conceitos de paisagem e região utilizados como base para a discussão sobre o objeto da geografia e seu papel diante das demais ciências. O espaço não se apresenta como conceito chave na geografia tradicional, porém as obras de Ratzel e de Hartshorne o apresentam de modo implícito (Corrêa, 1995). A discussão envolvia geógrafos vinculados ao positivismo e ao historicismo, além de geógrafos possibilistas, deterministas, culturais e regionalistas.

A Geografia teorético-quantitativa, calcada no positivismo lógico da década de 1950, introduziu profundas mudanças na geografia, como apontam, entre outros, James (1972), Claval (1974), Christofoletti (1976), Santos (1978) e Capel (1982) (CÔRREA 1995). Neste período, adotou-se uma visão de unidade epistemológica, unidade calcada nas ciências naturais. Os conceitos de lugar e região não apresentam grande significação, o espaço aparece pela primeira vez como conceito chave da disciplina e segundo Corrêa (1995), ocorrem em Bunge (1966), Schaefer (1953), Ullman (1954) e Watson (1955).

A década de 1970 foi marcada pelo surgimento da geografia crítica, fundada no materialismo histórico e dialético. Foi um dos períodos mais produtivos, pois a geografia crítica rompe com a geografia tradicional e com a geografia teoréticoquantitativa, criando seus próprios conceitos. É nesse período que surge a discussão entre marxistas e não marxistas acerca do espaço, em que se discute a

Revista de Estudos Sociais | Ano 2017, N. 39, V. 20, Pag. 55 
presença ou ausência do espaço na teoria social, a sua natureza e significado. $O$ espaço é abordado neste período como espelho externo a sociedade.

A década de 1970 foi o período no qual parecem as primeiras indagações da geografia crítica humana acerca da primazia da história sobre a geografia, fato que permaneceu adormecido por mais de uma década. A geografia pouco contribuiu em termos teóricos para essas primeiras reafirmações do espaço em contraposição do tempo, porém, a mais persistente e coerente dessas vozes espacializadoras foi de Henri Lefebvre.

Foi a incapacidade do historicismo de reconhecer a importância do espaço na construção da teoria social crítica que levou, no fim dos anos de 1970, ao nascimento do que Soja (1993) denomina "geografia humana critica pós-moderna".

\begin{abstract}
"A incapacidade desse debate de reconhecer a singular periferização teórica do espaço, que acompanhou até as formas mais neutras do historicismo, entretanto, foi justamente o que começou a ser descoberto no fim dos anos sessenta, nos titubeantes primórdios do que denominei de geografia humana crítica pós-moderna" (Soja, 1993, p.23).
\end{abstract}

Segundo Corrêa (1995), o espaço aparece efetivamente na análise marxista a partir da obra de Henri Lefebvre. Em seu livro Espacio y Política argumenta que o espaço "desempenha um papel ou uma função decisiva na estruturação de uma totalidade, de uma lógica, de um sistema" (Lefebvre, 1976, apud Corrêa, 1995, p. 25).

Nos anos oitenta, as tradições historicistas passam a ser questionadas, uma geografia humana pós-moderna e crítica vem tomando forma, reafirmando a importância interpretativa do espaço. O tempo não é mais o ponto de partida para a construção do pensamento crítico contemporâneo, mas a interação do tempo e do espaço, "a interação da história com a geografia, das dimensões "verticais" e "horizontais" do ser no mundo, livres da imposição do privilégio categórico intrínseco". (Soja, 1993 p. 19)

\footnotetext{
"Novas possibilidades estão sendo geradas a partir desse entrelaçamento criativo, possibilidades de um materialismo simultaneamente histórico e geográfico, de uma dialética tríplice de espaço, tempo e ser social, e de uma reteorização transformadora entre a história, a geografia e a modernidade". (Soja, 1993, p.19)
}

Dentro dessa nova perspectiva estão as obras de Milton Santos, que juntamente com as obras de Lefebvre, contribuíram para o estabelecimento do conceito de formação socioespacial no qual, modo de produção, formação socioeconômica e espaço são categorias interdependentes.

A discussão acerca da evolução da geografia como ciência nos é pertinente para entendermos que ao longo do desenvolvimento da história da ciência geográfica, os geógrafos se dedicaram muito mais a definição da geografia, do que na definição do seu objeto de estudo, o espaço, o que refletiu na forma como a geografia enquanto ciência evoluiu, adquirindo um caráter ideológico e não alcançando uma construção filosófica. 
Podemos considerar que essa ruptura teve seu início a partir da década de 1970, com o surgimento da geografia crítica, quando se inicia uma discussão acerca do espaço na teoria social, sua natureza e significado. Nesse sentido, foi a partir da concepção de espaço social, desenvolvida por Milton Santos, como instância social, que contém e está contida nas demais instâncias, construída a partir de uma lógica dialética, que a geografia conseguiu responder as indagações que a sociedade atual impõe ao seu objeto de estudo, perpassando pelo global e alcançando o local.

\section{Elementos da construção do paradigma atual da Geografia: 0 espaço Social}

É a partir da influência da noção de paradigma construído por KUHN (1962), que Milton Santos inicia a construção do novo paradigma da geografia, o espaço como instância social. Para Santos (2004, p. 195) a questão da identificação de um novo paradigma, estava além da condenação do velho paradigma, compreendia a submissão de todo o velho a uma renovação. Essa era uma questão que precisava ser revista dentro da história e incluía a observação dos fatos concretos e da forma como eles se apresentavam concretamente, o que imporia aos diversos especialistas um novo elenco de relações que vai permitir que o novo sistema de ideias seja retirado da própria realidade.

Para o autor cada vez que ocorre uma mudança organizacional ou social profunda, os modelos de percepção da realidade modificam-se substancialmente, "a cada mudança técnica, as verdades científicas do passado, devem ceder lugar a novas realidades científicas" (SANTOS, 2004, p.198)².

A história da humanidade sofre mudanças quantitativas e qualitativas, que representam uma nova combinação de técnicas, uma nova combinação de forças produtivas e, em consequência, um novo quadro para as relações sociais, que devem ser respondidas por novas verdades científicas, dentro dessa realidade é que ocorrem as reformulações metodológicas das ciências. E no caso da geografia, além da influência das mudanças sociais na reformulação da ciência, a interdisciplinaridade também teve um papel primordial para o alcance da sua formulação atual.

A história da busca da interdisciplinaridade aplicada à geografia, segundo Santos (2004, p. 134) reconhece três etapas, todas abortivas, e uma quarta que ainda está se delineando no qual a teoria de Milton Santos se enquadra.

O primeiro momento da interdisciplinaridade na geografia tem como base a interdisciplinaridade clássica, fundamentado nas ideias de Kant (1802, v.01, p. 6-8 apud Santos, 2004, p.134), no começo do século XIX, baseada em relações bilaterais entre geografia e história. A geografia se ocupava dos acontecimentos que se realizam simultaneamente no espaço, e a história relataria os acontecimentos que se sucedem no tempo, a diferenciação só ocorre em relação aos objetos analisados, o tempo e o espaço.

\footnotetext{
2 Está ideia de Santos está embasada em A. GRAMSCI, (1970, 1972, p. 13) que acredita que a própria visão do mundo corresponde a problemas delineados pela realidade, sendo determinados e originais da sua atualidade.
}

Revista de Estudos Sociais | Ano 2017, N. 39, V. 20, Pag. 57 
Segundo Santos (2004, p. 134), esta noção de que a história organiza os fenômenos no tempo e a geografia organiza os fenômenos no espaço, é responsável por um equívoco extremamente grave no domínio do método, a geografia deve ocupar-se em pesquisar como o tempo se torna espaço e de como o tempo passado e o tempo presente têm, cada qual, um papel específico no funcionamento do espaço atual.

A segunda etapa da interdisciplinaridade na ciência geográfica consistiu em um período negativo para a ciência, pois se caracteriza pela recusa dos geógrafos em aperfeiçoar conhecimentos provenientes de outras disciplinas. Esta fase está associada ao momento que os fundadores da geografia moderna passaram a ter como preocupação afirmar a geografia como ciência autônoma. A geografia humana francesa, que tinha Vidal de La Blache como seu fundador não concebeu a ideia de uma disciplina sociológica, que trata das transformações da sociedade no espaço geográfico, o que provocou uma profunda separação entre geografia e sociologia, levando ao empobrecimento da geografia e ao nascimento de disciplinas paralelas que poderiam estar sendo tratadas dentro da área de trabalho da geografia (SANTOS, 2004).

A terceira etapa da interdisciplinaridade na geografia, ganha uma nova abrangência depois de dois novos avanços na história, um no final do século XIX e outra muito mais brutal, depois da segunda guerra mundial, fatos que influenciaram no campo das ciências sociais, assim como no domínio das técnicas. O progresso científico e econômico criou novas realidades que exigiram explicações particulares levando ao surgimento de novas disciplinas científicas. As novas condições da ciência fazem com que aumente a possibilidade "de ajudar as ciências afins a progredir de fora para dentro com a contribuição das matérias vizinhas (Santos, 2004, p.136).

\footnotetext{
"Em realidade a lista de ciências chamadas afins da geografia que se escrevia acompanhada de nomes como história, sociologia, economia (se nos limitamos a geografia humana) tornou-se muito mais longa porque devemos acrescentar-lhe outros domínios do saber como a tecnologia (ciência das forças produtivas), a ciência política, o urbanismo, a técnica gerencial, a semiologia, a epistemologia, os negócios internacionais, a história das ciências, a ciência das ciências, chamada cienciologia, e mesmo a lógica e a dialética" (Santos, 2004, p. 137)
}

A necessidade de se alcançar esta cooperação entre as disciplinas, levou a busca de diversos caminhos para o desenvolvimento da pesquisa. Uma das tentativas de se construir a interdisciplinaridade foi a construção de uma espécie de trabalho de pesquisa cooperativo, no qual especialistas de diversas áreas seriam convocados para trazer consigo sua bagagem metodológica própria, a fim de oferecer múltiplas contribuições e a geografia seria uma das disciplinas contribuintes.

Para Piaget (1972) apud Alvarenga et al. (2011), esta interação entre formas especificas de conhecimento para além do disciplinar é denominada multidisciplinaridade, que o autor trata de "patamar inferior" de interação, quando não ocorrem interações propriamente ditas, mas a aquisição de conhecimento a partir de grupos de pesquisadores que dispõem suas informações de forma mútua e cumulativa. Japiassu (1976) denomina esse tipo de interação interdisciplinar de

Revista de Estudos Sociais | Ano 2017, N. 39, V. 20, Pag. 58 
"interdisciplinaridade compósita", quando ocorre somente uma conjugação de disciplinas por aglomeração, cada uma dando as suas contribuições, mas guardando a autonomia e a integridade de seus métodos, de seus conceitos-chaves e de suas epistemologias.

A busca do entendimento da complexidade que a sociedade atual nos apresenta, necessita de uma nova forma para alcançar tal explicação, e a geografia também se enquadra nessa necessidade, sendo assim busca-se uma nova forma de construir interdisciplinaridade, que ultrapasse os muros das ciências ditas "estruturadas" na busca de uma reconstrução filosófica, que inclua o que Oliveira Filho (1976), chama de "Axiomática comum".

Para Piaget (1972) apud Alvarenga et al. (2011, p. 26) a interdisciplinaridade trata-se de um "segundo nível" de colaboração entre disciplinas diversas ou entre setores heterogêneos de uma mesma ciência, que conduz a uma interação maior, onde existe uma reciprocidade entre trocas que resultaria na busca de estruturas mais profundas.

Dentro desta nova realidade imposta pelos acontecimentos científicos pós II guerra, quando se estabelece a necessidade da interdisciplinaridade como ferramenta para responder aos problemas que a sociedade apresentava, e diante de todas as teorias sobre o assunto que se estabeleciam, mas precisamente a partir da década de 1970, Milton Santos inicia a reestruturação da ciência geográfica, dentro de uma reflexão de "cientista filósofo", conforme (Oliveira Filho, 1976), completando a quarta etapa da interdisciplinaridade no desenvolvimento da ciência geográfica.

Segundo Santos (2004, p.141) se faz necessário que se reconheça um objeto para a geografia, e que se hajam identificados suas categorias fundamentais, mesmo que as categorias mudem de significação com a história, elas são também uma base permanente para a teorização, que no caso da geografia é a produção do espaço.

\begin{abstract}
"A interpretação do espaço e sua gênese ou seu funcionamento e sua evolução depende de como façamos antes a correta definição de suas categorias analíticas, sem a qual estaríamos impossibilitados de desmembrar o todo através de um processo de análise, para reconstruí-lo depois através de um processo de síntese. Sem isso, não seria mesmo possível pensar em trabalho interdisciplinar, porque não teríamos os meios para reconhecer, em cada ocasião, quais as outras disciplinas científicas que podem vir em nosso auxílio e trazer-nos uma colaboração. Que tipo de colaboração pode cada uma delas nos oferecer? Que uso podemos fazer de seus ensinamentos? Em outras palavras, não são todas as ciências particulares nem é toda uma ciência particular que entram como componentes da interdisciplinaridade própria a cada outra ciência" (Santos, 2004, p. 148)
\end{abstract}

Dentro deste contexto a definição do objeto da geografia segundo Santos (2004, p. 149), consiste em construir um sistema próprio de identificação das categorias analíticas que reproduzem no âmbito da ideia, a totalidade dos processos tal como eles produzem a realidade. 


\section{Reconstrução metodológica da geografia atual a partir de seus pressupostos epistemológicos, lógicos e ontológicos.}

Entramos no momento que corresponde à construção da metateoria da geografia atual, que tem como objeto o espaço social. Segundo Oliveira Filho (1976, p. 270), uma "reconstrução metodológica é adequada e significativa enquanto reconstrução metodológica de um determinado processo de investigação". Busca-se os "fundamentos" da geografia, o conjunto de pressupostos lógicos, epistemológicos e ontológicos da atividade científica em investigação que, segundo Oliveira Filho (1976, p. 270), apresentam duas funções: a) descritiva ou b) crítica de intervenção e reorientação das estratégias de investigação, no caso a reconstrução realizada no presente texto tem como função a descrição.

Neste caso será realizado uma análise descritiva, a partir do que Oliveira Filho (1976) denominou "esquema base" que opera em um determinado momento da história da geografia, o período atual, tendo como base o espaço social.

Segundo Milton Santos (2008), a preocupação da construção epistemológica da geografia atual tem como base a totalidade. Sua investigação partiu de realidades concretas, mas sua exposição teórica tem como ponto de partida a sociedade humana em processo.

Levando em consideração a condição ontológica apontada por Oliveira Filho (1976), que está antes de tudo baseada no fato de que a atividade do cientista social pressupõe a existência de uma realidade objetiva a ser investigada, ainda que essa "objetividade" seja apenas uma aproximação e uma condição linguística materializada em um sistema teórico, a teoria do espaço social desenvolvida por Milton Santos apresenta como aspecto ontológico, a sociedade humana em processo. Essa sociedade humana em processo, em qualquer momento se realiza sobre uma base material, o espaço e seu uso, o tempo e seu uso, a materialidade e suas diversas formas, as ações e suas diversas formas.

A forma de acessar o conhecimento na geografia, dentro da construção metateórica desenvolvida por Milton Santos, ocorre através da abordagem da sociedade através da categoria do espaço. A base de ideia de espaço ocorre sobre a lógica dialética apropriada da noção de dialética de Hegel, e mais claramente da noção de natureza naturans e natureza naturata, que Santos (2008) denomina primeira natureza e segunda natureza, elaborada pela filosofia clássica alemã, como uma categoria central que distingue polemicamente a dialética da metafísica. A natureza naturans é a natureza tal qual ela está agora, isto é, no tempo 1, natureza naturata é a natureza como se apresenta no tempo imediato ou tempo 2.

Este constitui o principio dialético do espaço, existe sempre uma primeira natureza prestes a se transformar em segunda, uma depende da outra, porque natureza segunda não se realiza sem as condições da natureza primeira e a primeira é sempre incompleta e não se perfaz sem que a natureza segunda se realize.

Segundo Santos (2008, p.63) o conceito de espaço pode assim ser definido: 
"O espaço é formado por um conjunto indissociável solidário e também contraditório de sistemas de objetos e sistemas de ações, não considerados isoladamente, mas como o quadro único no qual a história se dá".

O espaço assim definido é considerado um fator de evolução social, não apenas uma condição, o espaço é considerado uma instância da sociedade, ao mesmo tempo em que a econômica e a instância cultural-ideológica. Sendo assim, o espaço como instância contém e está contido pelas demais instâncias, assim como cada uma delas o contém e por ele está contido (Santos, 2008a, p. 12). O espaço não é formado somente pelas coisas, pelos objetos naturais e artificias, cuja natureza nos dá, o espaço constitui tudo isso, mais a sociedade, onde cada fração da natureza obriga uma fração da sociedade atual.

O diferencial e inovador na teoria de Milton Santos é a explicação do espaço a partir da sociedade, onde os processos sociais dão vida aos objetos do espaço, dando origem a uma configuração espacial representativa em um dado momento. Sendo assim, a resposta ocorre porque os processos sociais resolvidos em funções realizam-se através de formas, neste caso, como as formas geográficas contém frações do social, não são apenas formas, mas formas-conteúdo (Santos 2008a p.12).

Estas formas-conteúdo estão em constante modificação, na "medida que o movimento social Ihes atribuir a cada momento frações diferentes do todo social" (Santos, 2008a, p. 13). A relação forma-conteúdo também é dialética, correspondendo o movimento dialético do todo social, apreendido na e, através da realidade geográfica. Dentro deste contexto é possível apreender o imenso movimento do mundo em um ponto geográfico, o lugar. Cada localização é, pois, um movimento do imenso movimento do mundo apreendido em um ponto geográfico, um lugar.

O tempo no espaço aparece empiricizado, tornando-se material e desse modo assimilado ao espaço que não existe sem a materialidade. A técnica entra como um traço de união histórica e epistemológica (Santos, 2008a, p. 54). As técnicas de um lado possibilitam a empirização do tempo, e de outro possibilitam a qualificação precisa da materialidade sobre a qual as sociedades humanas trabalham. Essa empirização pode ser a base de uma sistematização solidária com as características da época, porém ao longo da história, as técnicas se organizam como sistemas diferentemente caracterizados. A técnica na teoria de Milton Santos aparece como uma união entre o espaço e o tempo, pois é por intermédio da técnica que o homem modifica através do seu trabalho o espaço.

Dentro deste contexto as noções de trabalho e de instrumento de trabalho são muito importantes na explicação geográfica, o trabalho realizado em cada época supõe um conjunto historicamente determinado de técnicas, herança de Marx (Capital I, p. 132 in Santos, 2008a, p. 56) "que afirma que o que distingue as épocas econômicas das outras não é o que se faz, mas como se faz, com que instrumentos de trabalho".

Segundo Santos (2008a, p. 56) "esta noção tem, pois, um valor histórico e espacial", pois cada lugar geográfico concreto corresponde, em cada momento, um 
conjunto de técnicas e de instrumentos de trabalho, resultado de uma combinação específica que é historicamente determinada.

\section{A teoria Miltoniana como suporte para o entendimento das especificidades do urbano na Amazônia}

Apesar dos fenômenos sociais, políticos e econômicos parecerem uniformes para toda a região amazônica, a combinação dos elementos, a partir dos diversos atores envolvidos, ocorre de forma diferenciada ao longo do tempo, o que confere ao espaço urbano formas/conteúdos diferenciados.

Dentro desta realidade, para que haja um entendimento das particularidades e especificidades do urbano na Amazônia como espaço periférico, é necessária uma análise multiescalar que permita entender como os diferentes elementos atuam em cada escala, assim como uma análise interna da cidade que permita entender como a ação de cada um destes elementos estão presentes na sua constituição interna.

O método de análise geográfica, incluindo os conceitos de economia política da urbanização e economia política da cidade, permite uma distinção entre o urbano e cidade. O urbano é frequentemente o abstrato, o geral, o externo o qual atribuímos a uma leitura mais geral, associado às grandes mudanças históricas. A cidade corresponde ao particular, o concreto, o interno que inclui uma escala mais reduzida.

Tanto o estudo referente à urbanização quanto à cidade exige a necessidade de articular o conceito de espaço, que como categoria histórica muda seu conceito a cada nova variável que vai sendo acrescentada no curso do tempo. O referencial teórico, base para um estudo aprofundando da cidade que englobe desde o processo de urbanização até a organização intraurbana da cidade, é a economia política, cujo objeto é o estudo da produção, de suas condições de realização e de suas consequências diversas como resultado de um jogo complexo que envolve o funcionamento do capital e do trabalho (Santos, 2009, p.111).

Contudo, a economia política não pode dissociar-se do espaço, que pode ser definido como o resultado de uma interação permanente entre trabalho acumulado, na forma de infraestruturas e máquinas que se sobrepõe a natureza, e de outro o trabalho presente distribuído sobre essas formas provenientes do passado.

A cidade é o local em que se materializam todos estes processos, pois constitui um grande meio de produção material e imaterial, lugar de consumo e de comunicação. Para o entendimento deste processo global de produção que se materializa na forma como a cidade está estruturada, é necessário o entendimento do processo de urbanização, a partir de uma análise multiescalar juntamente com uma análise intraurbana, da forma como os processos se materializam na cidade.

O método de análise proposto por Milton Santos (2008a) para a análise das variáveis que compõem o espaço é a periodização, pois o mesmo considera a mudança dos períodos históricos, a mudança dos modos de produção e as variáveis que compõem o espaço. 
A periodização proposta por Santos (2008b) ocorre a partir do conceito de período, "que correspondem a pedaços de tempo submetidos à mesma lei histórica, com a manutenção das estruturas". As estruturas são definidas como "conjuntos de relações e de proporções prevalentes ao longo de certo pedaço de tempo e nos permite definir nosso objeto de análise" (Santos, 2008b, p.67).

A periodização proposta inclui diversas escalas de observar o mundo como um todo, a formação social e econômica, representado pelo Estado e a Nação, e a cidade que permitirá uma periodização, em um nível inferior.

Segundo Santos (2008b, p. 67):

"A cidade, é ao mesmo tempo, uma região e um lugar, porque ela é uma totalidade, e suas partes dispõem de um movimento combinado, segundo uma lei própria, que é a lei do organismo urbano, com o qual se confunde. $\mathrm{Na}$ verdade, há leis que se sucedem, denotando o tempo que passa e mudando as denominações desse verdadeiro espaço-tempo, que é a cidade".

Sendo assim, são as categorias do espaço-tempo dentro do contexto da periodização permitem juntar estes dois universos de pesquisa; a cidade e o urbano. A leitura a partir da economia política da urbanização, juntamente com uma leitura da formação sócio espacial, dentro do contexto das forças internas e externas de atuação sobre o espaço, permitem uma análise em que a divisão social do trabalho, juntamente com a divisão territorial do trabalho, possa definir a repartição dos instrumentos de trabalho, do emprego e dos homens em um determinado espaço, dentro de um recorte regional, a partir dos contextos nacionais e mundiais.

A economia política da cidade permitirá uma análise intrarregional, que possibilita entender como a cidade se organiza internamente face a produção e como os diversos atores da vida urbana se localizam em cada momento da história.

Apesar de serem tratadas e analisadas separadamente, em uma análise urbana a economia política da urbanização e a economia política da cidade são inseparáveis. Eles se distinguem de um ponto de vista analítico, mas são de fato inseparáveis, porque a urbanização não é apenas um fenômeno social, ou econômico ou político, mas também um fenômeno espacial. Qualquer forma de repartição do espaço depende da forma como os instrumentos de trabalho e os fatores de produção se distribuem, sendo assim, existe uma relação de causa e efeito entre a cidade como ela se organiza materialmente, e como se dá o seu processo de urbanização (Santos, 2009).

A economia política da urbanização considera diversas escalas como base de análise, levando em conta a divisão social do trabalho que ocorre com a divisão territorial do trabalho com a repartição dos instrumentos de trabalho, dos empregos e dos homens.

As categorias de divisão territorial do trabalho e divisão social do trabalho precisam ser desenvolvidas a partir da "lei do desenvolvimento desigual e combinado", formulado por Trotsky (1982), que relaciona dois processos, desigualdade e combinação, que apesar de opostos e diferentes, possuem racionalidades que coexistem e se relacionam mútua e contraditoriamente.

O conceito de desenvolvimento desigual e combinado apresenta uma dimensão espacial, que dentro da uma análise geográfica pode se traduzir em análises de regionalização, desigualdade do desenvolvimento entre nações, entre

Revista de Estudos Sociais | Ano 2017, N. 39, V. 20, Pag. 63 
setores da economia de um país, materializando-se no espaço de maneiras distintas, resultando em organizações diferenciadas do espaço em diferentes escalas.

\section{Conclusão}

A reconstrução da metateoria desenvolvida por Milton Santos, a partir da leitura do espaço, levando em consideração os aspectos epistemológicos, lógicos e ontológicos permite identificar que os conceitos e teorias do universo da disciplina de geografia, conseguem responder à questão da diversidade do urbano na Amazônia.

As singularidades que permeiam as realidades urbanas da região amazônica estão relacionadas a um conjunto de normas que regem a organização do espaço e da sociedade amazônica, no sentido de manter o controle sobre as atividades econômicas, que se traduzem em cada realidade específica na forma como as fronteiras vão sendo incorporadas. Traduzindo-se na construção das diversidades territoriais, associadas a aplicação dos programas nacionais e de desenvolvimento regional, incorporados a partir dos interesses do capital, nacional ou internacional, construídos e implantados em nível de região, que quando adentram o nível local, resultam em um conjunto de práticas (psicoesfera) e nas suas expressões materiais (tecnoesfera), responsável pela construção daquilo que compreende um especificidade do processo de urbanização das cidades, ou seja, a expressão da sua identidade.

A questão da complexidade do fenômeno urbano amazônico consegue ser alcançada a partir do tripé; espaço, tempo e técnica e os aspectos referentes a condição periférica do espaço estudado, também consegue ser resolvida pelo conceitual proposto, pois a teoria desenvolvida por Milton Santos teve como foco as regiões consideradas subdesenvolvidas.

Como a construção das singularidades incluem a expressão material da cidade, se faz imprescindível entender os processos históricos de construção das cidades analisadas, pois a formação socioespacial responsável pela construção inicial das cidades foram determinantes para a escolha destas, como receptoras dos processos de incorporação da fronteira, assim como na forma como o processo de urbanização se desenvolveu

As categorias de análise da geografia nos permitem compreender as especificidades da construção dos espaços urbanos amazônicos, dentro das suas particularidades a partir de uma leitura multiescalar que possibilita identificar como os diferentes elementos sociais, políticos, econômicos e sociais se organizam na composição do espaço, levando ao entendimento das diferenças e semelhanças

\section{Referências Bibliográficas}

ALVARENGA, A. T. de; PHILIPPI JÚNIOR, A.; SOMMERMAN, A.; ALVARES, A. M. de S.; FERNANDES, V. Histórico, fundamentos filosóficos e teórico-metodológicos da interdisicplinaridade. In: PHILLIPPI Jr. A.; NETO, A.J.S. Interdisicplinaridade em ciência, tecnologia\& inovação, Barueri-SP, Manole, 2011, p. 3-68.

Revista de Estudos Sociais | Ano 2017, N. 39, V. 20, Pag. 64 
CORRÊA, R. L. Espaço: um conceito chave na Geografia. In: Geografia: conceitos e temas. 1995 .

JAPIASSU, H. Interdisciplinaridade e patologia do saber. Rio de Janeiro: Imago, 1976, p. 39-113, 220p.

HARVEY, D. A condição pós-moderna. São Paulo: Edições Loyola, 2006. 15a edição.

MACHADO, M. S. Geografia e Epistemologia: Um Passeio pelos Conceitos de Espaço, Território e Territorialidade. Revista do Departamento de Geografia. Rio de Janeiro: UERJ, n.1, p. 17-32, 1997.

OLIVEIRA FILHO, J. J. de. Reconstruções Metodológicas de Processos de Investigação Social. Revista de História (FFLCH-USP), n. ${ }^{\circ} 107$, vol. LIV, ano XXVII, jul-set, p. 263-276, 1976.

SANTOS, M. Por uma nova Geografia. São Paulo: Hucitec, 2004. 6ª edição. 285 p. Espaço e Método, São Paulo: Editora da USP, 2008. 5ª edição, $118 \mathrm{p}$

A Natureza do Espaço: Técnica e Tempo. Razão e Emoção. São Paulo: Editora da USP, 2008a. 4ª edição, $384 \mathrm{p}$. edição, $174 \mathrm{p}$.

Técnica, Espaço, Tempo. São Paulo: Editora da USP, 2008b. 5a

Por uma Economia Política da Cidade. São Paulo: Editora da USP, 2009. $2^{\mathrm{a}}$ edição, $139 \mathrm{p}$.

SOJA, E. W. Geografias Pós-Modernas: A reafirmação na Teoria Social Crítica. Rio de Janeiro: Jorge Zahar, 1993.

TROTSKY, L. A história da revolução russa. Disponível em http://www.marxists.org/portugues/trotsky/1930/historia/cap01.htm. Acesso em 05 de setembro de 2011. 